\title{
ERRATUM
}

Montserrat Vilà · Anna Gómez · John L. Maron

\section{Are alien plants more competitive than their native conspecifics? A test using Hypericum perforatum $\mathrm{L}$.}

\section{Oecologia (2003) 137:211-215}

Fig. 1 was incorrect and is given correctly here

Fig. 1
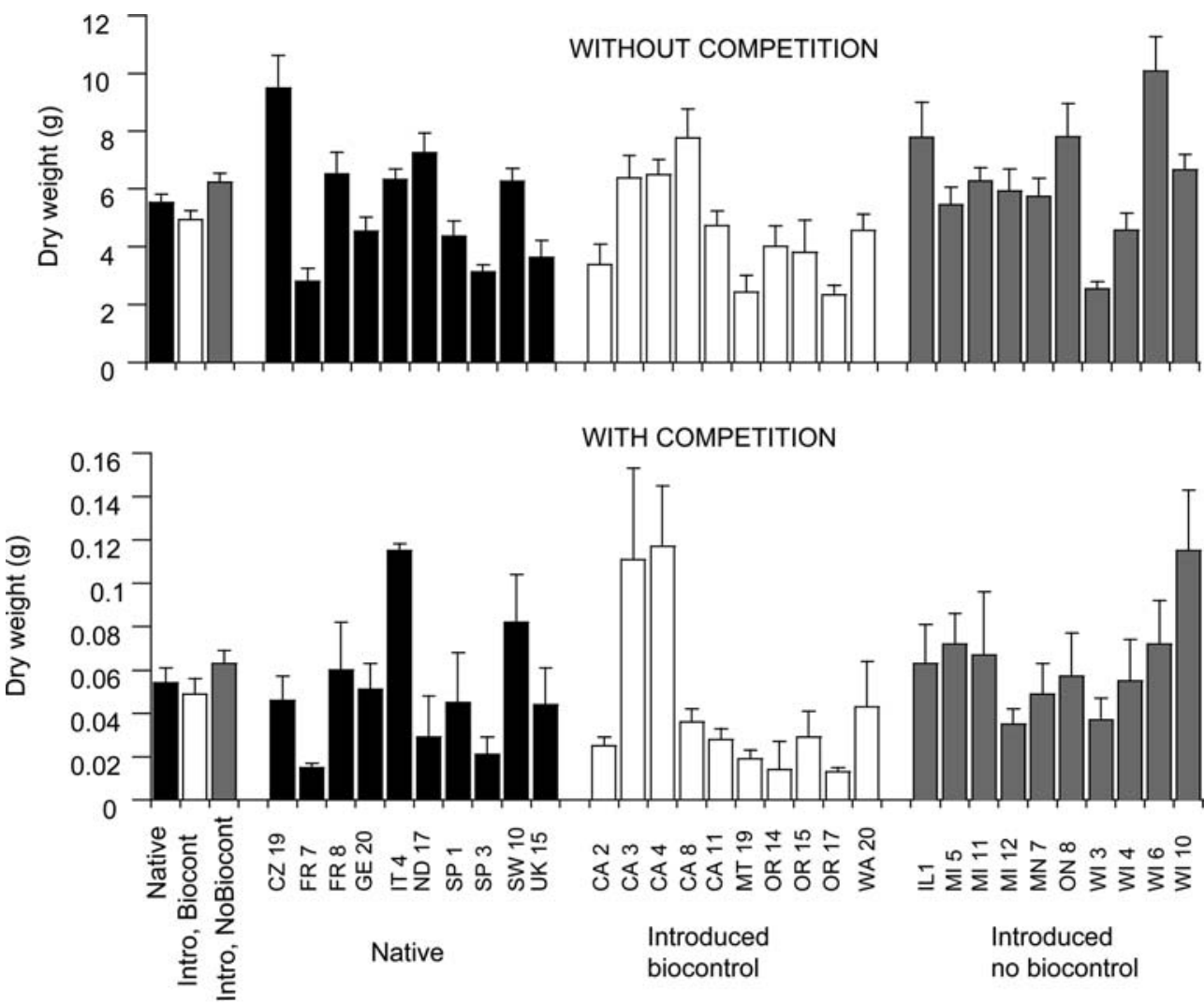

Populations

The online version of the original article can be found at http:// dx.doi.org/10.1007/s00442-003-1342-0

\section{Vilà $(\bowtie) \cdot A$. Gómez}

Centre de Recerca Ecològica i Aplicacions Forestals,

Universitat Autònoma de Barcelona, 08193 Bellaterra, Spain

E-mail: montse.vila@uab.es

Fax: + 93-5814151
J. L. Maron

Division of Biological Sciences, University of Montana, Missoula, MT 59812, USA 